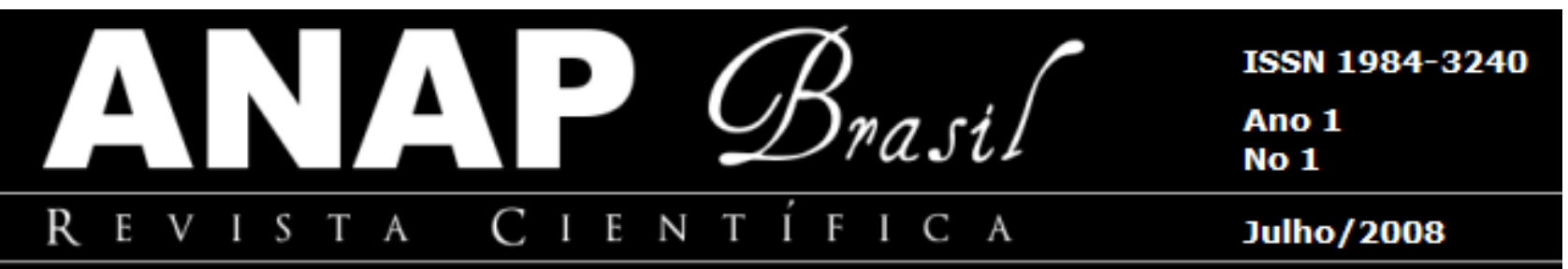

\title{
TURISMO ÉTNICO - CONCEITOS E PRÁTICAS: UMA PROPOSTA PARA O CAFUNDÓ, EM SALTO DE PIRAPORA - SP
}

Maria Alice Gaiotto ${ }^{1}$

RESUMO: Ancorado nos conceitos de Geografia e Território, com ênfase nos tradicionais Quilombolas, esse artigo apresenta uma proposta para a comunidade Cafundó, localizada em Salto de Pirapora, no sudoeste paulista. Sistematizado nos pressupostos teóricos do Turismo Étnico, o projeto pretende traçar possíveis estratégias em busca de soluções planejadas para as atividades do turismo, dentro do paradigma da sustentabilidade sociocultural, econômica e ambiental, considerando os condicionantes e o território da bacia hidrográfica. A finalidade na definição das intervenções contempla a participação dos seus moradores no processo de planejamento turístico e de uso e ocupação dos solos. Pretende servir ao desenvolvimento como um todo, mas também à valorização da cultura caipira cafundoense, representada principalmente no dialeto africano "cupópia" ou "falange" e nos exemplares da "arquitetura vernacular", ameaçados de extinção e/ou destruição. O resgate histórico e a conservação dos usos e costumes, favoráveis às atividades turísticas, devem colaborar com a preservação e a conservação do patrimônio cultural como ordenador da paisagem do Cafundó.

Palavras-chave: Turismo Étnico. Comunidade Quilombola. Cafundó.

\section{INTRODUÇÃO}

\footnotetext{
${ }^{1}$ Arquiteta e Urbanista, Doutora pela FAU-USP/SP, Monitora do SENAC-Sorocaba, Aluna do Curso de Especialização em Professor de Turismo: Centro de Excelência em Turismo: Universidade de Brasília. Email maria_alicegaiotto@yahoo.com.br
} 


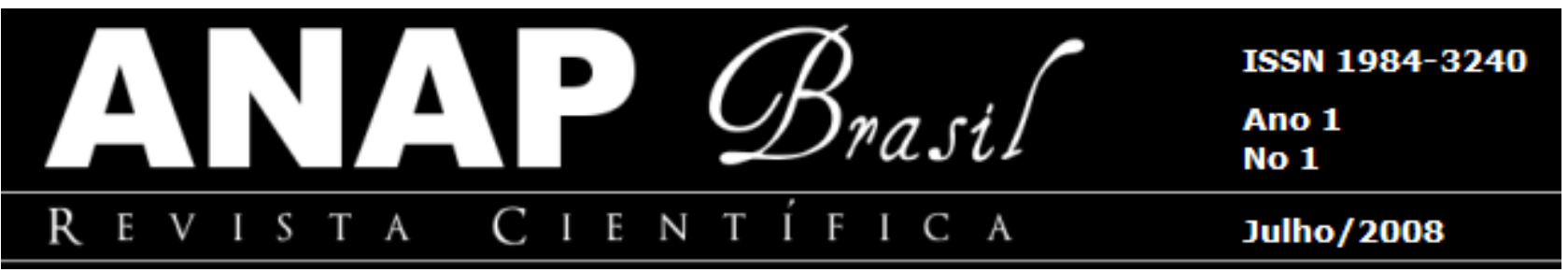

O Programa Egbé Territórios Negros de Koinonia, do Observatorório Quilombola (OQ, 2008), evidencia o art. 68, da Constituição Federal de 1998: "aos remanescentes das comunidades de quilombos que estejam ocupando suas terras, é reconhecida a propriedade definitiva, devendo o Estado emitir-Ihes títulos respectivos".

O "termo quilombo", antes vinculado "ao conceito histórico de grupos formados por escravos fugidos", passa a "designar a situação dos segmentos negros em diferentes regiões e contextos no Brasil, fazendo referência a terras que resultaram da compra por negros libertos; da posse pacifica por ex-escravos de terras abandonadas pelos proprietários em épocas de crise econômica; da ocupação e administração das terras doadas aos santos padroeiros ou de terras entregues ou adquiridas por antigos escravos organizados em quilombos". (OQ, 2008)

Isto posto, para o desenvolvimento dessa proposta, a escolha do Cafundó devese à tomada de consciência a partir dos ensinamentos do Dr. Rafael Sanzio (ARAÚJO DOS ANJOS, 2008), defensor dos quilombolas enquanto populações nativas, resultantes não apenas do passado escravista, isoladas no tempo e no espaço, sem qualquer participação na estrutura social brasileira; mas, ao contrário, as mais de duas mil dessas comunidades tradicionais, espalhadas pelo território brasileiro mantêm-se vivas, inclusive, na constante luta pelos direitos de uso e ocupação das suas terras, além da manutenção das suas manifestações culturais.

Ao vislumbrar a identificação do patrimônio histórico-cultural para uma proposta de Turismo Étnico nessa comunidade quilombola, pretende-se englobar os saberes e as manifestações das suas parentelas, Pires Cardoso e Almeida Caetano, seja, através da lógica do sistema capitalista, também fundamental na definição do seu panorama físicoterritorial e econômico, como dos fenômenos migratórios recorrentes, principalmente após a abolição da escravatura, que desde a cafeicultura, no Século XIX, à atualidade da diversificação dos processos produtivos influi significativamente no desenvolvimento dessa porção da bacia do Sorocaba/Médio Tietê, onde se localiza o Cafundó.

Nesse artigo, num primeiro momento, apresentam-se as especificidades e pressupostos teóricos da Geografia e do Território, com ênfase nos tradicionais das comunidades quilombolas, para depois dos fundamentos do Turismo Étnico, pautados na breve revisão sobre hospitalidade e sustentabilidade sócio-econômica, histórico-cultural e 


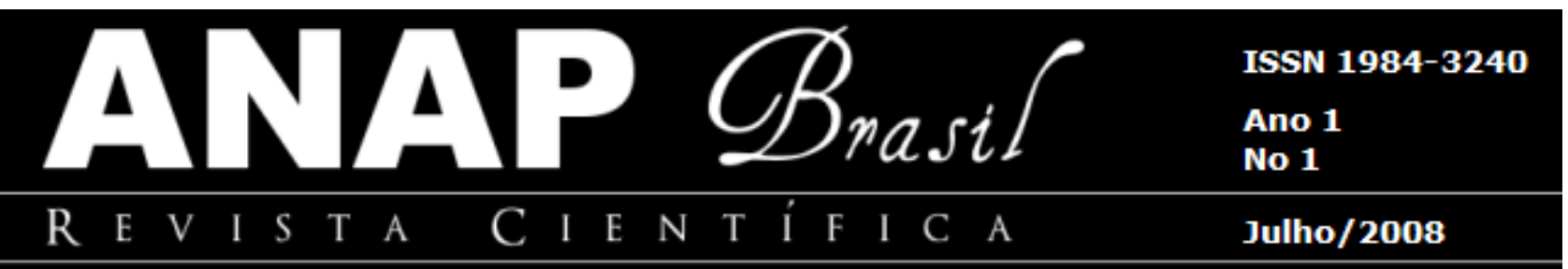

ambiental, buscar o devido suporte às diretrizes e estratégias para as atividades de turismo no Cafundó.

Essa proposta apresenta finalidades cognitivas mais amplas na definição de intervenções planejadas e participativas, pois pretende servir ao desenvolvimento das atividades do turismo sustentado, mas também à valorização da cultura cafundoense, representada, principalmente pelo dialeto africano "cupópia" ou "falange" e pelos exemplares da "arquitetura vernacular", atualmente ameaçados de destruição. Assim, o resgate histórico e a conservação dos usos e costumes, favoráveis ao Turismo Étnico, visam colaborar com a preservação do seu patrimônio cultural como ordenador da paisagem do Cafundó.

\section{DELIMITAÇÃO E CARACTERIZAÇÃO DO OBJETO DA PESQUISA}

A Lei 7663/91 estabeleceu vinte e duas Unidades de Gerenciamento de Recursos Hídricos (UGRHI) no Estado de São Paulo. A UGRHI 10 abrange trinta e quatro municípios, dos quais dezesseis, localizam-se na Bacia do Médio Tietê, e dezoito, na do Sorocaba, cujo trecho superior está no Planalto Atlântico e o restante, na Depressão Periférica ("Grupo Tubarão"), inseridos no Bioma Mata Atlântica, na porção sudoeste paulista. (GAIOTTO, 2002).

Para a finalidade desta proposta, será considerada somente parte da Bacia do Baixo Rio Sorocaba, que compreende a área drenada pelos afluentes, o Sarapuí e o Pirapóra, que engloba, total ou parcialmente, além de Salto de Pirapora, onde se localiza o Cafundó, os municípios de Sarapui, Araçoiaba da Serra e Capela do Alto.

Nessa região, devido à vocação comercial de animais, no "Período do Tropeirismo", e agricultura de subsistência, a mão-de-obra escrava não foi tão expressiva, se comparada ao restante do Estado. O entreposto comercial de Sorocaba, mesmo após a proibição do tráfico, em 1830, também negociava escravos, e a maior parte das comunidades quilombolas da região constitui-se de terras adquiridas por ex-escravos ou doadas pelos seus senhores. Assim, nas suas vizinhanças encontram-se algumas comunidades remanescentes dos tradicionais quilombos, tais como o "Cafundó", a mais 


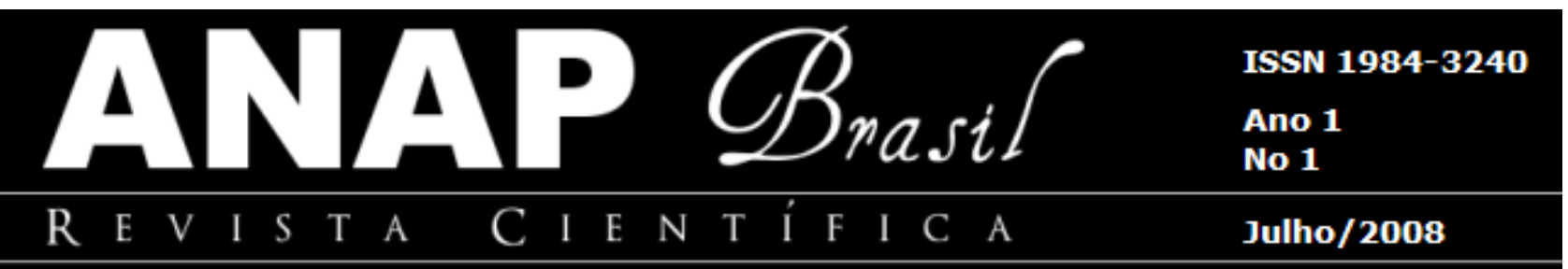

conhecida devido o seu patrimônio cultural, o dialeto africano "cupópia" ou "falange"; além de "Piraporinha" e "Fazendinha dos Pretos", em Salto de Pirapora; "Carmo", em São Roque; "Fazendinha Pilar", em Pilar do Sul, e "Os Camargo", em Votorantim. (ANDRADE FILHO, 2008)

\subsection{CAFUNDÓ: COMUNIDADE TRADICIONAL QUILOMBOLA}

Ancorado no Historiador Rodrigo ARAÚJO (2008), devido à organização econômica e estrutura social, pode-se afirmar que a comunidade Cafundó se assemelhava a uma "aldeia angolana", indicador de sua origem africana.

No final da década de 70 , graças às pesquisas acadêmicas, entre outras conseqüências, atraíram os meios de comunicação e o patrimônio cultural, divulgado e valorizado, resulta em intervenções políticas no Cafundó, bem como dos movimentos sociais, cujos olhares, voltados para a principal singularidade: o léxico de origem africana, "cupópia" ou "falange", dialeto falado por alguns dos seus moradores, que levou à consideração dessa comunidade enquanto reduto do período escravocrata que permaneceu intacto (VOGT \& FRY, 1996). No entanto, equivocam-se, pois longe de estar isolada ou intocada, essa comunidade quilombola tem passado pelas conseqüentes invasões de terras e convive na incessante luta para garantir os seus direitos de uso e posse do território (ANDRADE FILHO, 2008).

Quanto à origem do Cafundó, os seus moradores relatam que, nos idos de 1888, os ex-escravos, Joaquim Congo e Ricarda, receberam do antigo dono, José Manoel de Oliveira, o primeiro quinhão de terra para o trabalho livre. Posteriormente, o casal trocou essas terras pela área, onde atualmente se situa a comunidade. Antônia e Ifigenia, filhas de Ricarda e Joaquim Congo, permaneceram no Cafundó e deram origem a duas parentelas: os Almeida Caetano e os Pires Cardoso. Antônia casou-se com Joaquim Pires Cardoso, e Ifigenia, com Caetano Manoel de Oliveira, que morava na vizinha e extinta comunidade Caxambu. As relações entre o Cafundó e o Caxambu foram intensas, inclusive em casamentos entre seus membros. A partir 1940, essas áreas sofrem interferências do mercado imobiliário e das invasões e grilagens dos fazendeiros vizinhos, 


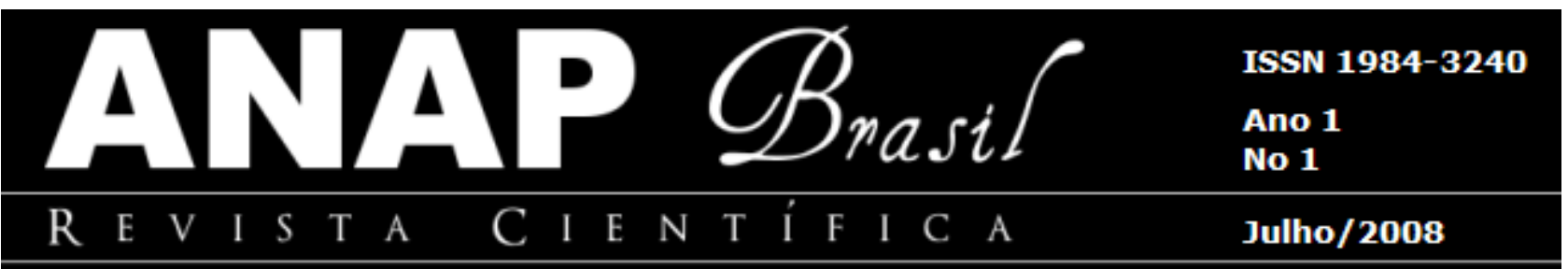

entre outros, que exterminaram o Caxambu e, sensivelmente, diminuíram o Cafundó, que permanece com menos de um quarto do território original e continua na luta para conseguir de volta o que the foi tomado. (VOGT \& FRY, 2005)

Os herdeiros, atuais moradores dessa comunidade, ocupam aproximadamente vinte e um hectares remanescentes dos duzentos e dezoito hectares originais. A garantia do direito de propriedade dessas terras apresenta-se em moroso processo, pautado em diversos conflitos, inclusive mortes, ameaçadores do seu bem estar. Em 1990, o Conselho de Defesa do Patrimônio Histórico, Artístico, Arqueológico e Turístico de São Paulo (CONDEPHAAT), em função da importância do Cafundó como bem cultural de valor histórico, tombou essa comunidade, em aproximadamente oito hectares de sua área total. No entanto, esse procedimento não garantiu a preservação dos seus costumes e cultura. Em 1999, teve início o processo de regularização dessas terras pela Fundação Instituto de Terras do Estado de São Paulo "José Gomes da Silva" (ITESP), em cujo levantamento, o território do Cafundó se encontra totalmente sobreposto aos domínios particulares. Em 2004, abriu-se um processo de regularização das terras junto ao INCRA, e após dois anos, a Portaria 235/2006 reconhece o total do território cafundoense, em 218,4462 hectares (PINHEIRO, 2004).

As dificuldades para garantir a sobrevivência dos moradores do Cafundó, bem como o reduzido tamanho de sua área original, entre outros fatores, limitam as possibilidades de produção agrícola e de geração de renda, situação que os obriga aos empregos, como pedreiros, jardineiros, caseiros e cortadores de eucalipto, entre outros, nas demais propriedades da região. Nas áreas cultivadas para a subsistência da comunidade encontram-se as roças periódicas de feijão, milho e mandioca, e criam-se os animais, como aves (frangos e galinhas), suínos e bovinos. (ANDRADE FILHO, 2008)

As casas, remanescentes da área tombada como patrimônio cultural, dispostas em forma circular, abrigam as duas parentelas: de um lado, a dos Pires Cardoso, e do outro, dos Almeida Caetano. Casas de "pau-a-pique" com o chão de terra batida, além de uma Capela, situada logo na entrada da comunidade, são as construções mais antigas. A partir da década de 80 , outras casas foram construídas de alvenaria, com a ajuda financeira de diversas entidades e do poder público local. (VOGT \& FRY, 1996) 


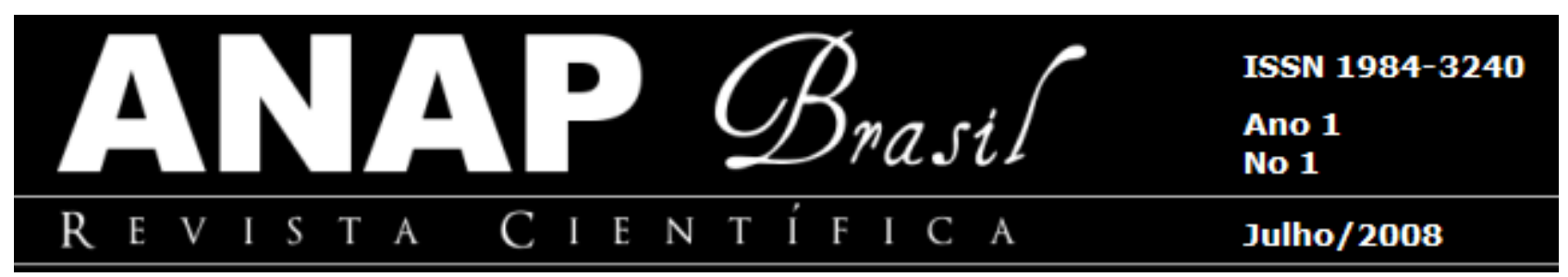

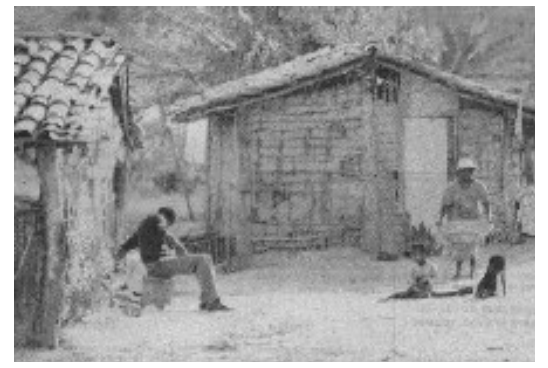

Figura 1 - Casas de "pau a pique" Fonte: ARAÚJO (2008)

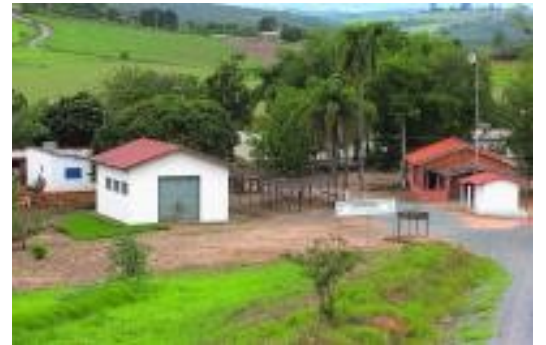

Figura 2 - Casas de Alvenaria Fonte: PINHEIRO (2007)

Ali, no mês de maio, realiza-se a Festa de Santa Cruz, que comemora a abolição da escravatura, na qual participam os seus moradores e a vizinhança, além dos turistas, oriundos das mais distantes localidades. (ANDRADE FILHO, 2008)

A língua africana do Cafundó, o dialeto conhecido como "falange" ou "cupópia", possui um vocabulário limitado em aproximadamente cento e quarenta palavras, sendo que a maioria delas tem origem no "quimbundo", cuja raiz está no "banto angolano". Carlos VOGT e Peter FRY (1996) exemplificam o "aportuguesamento na estrutura sintática e no uso das palavras da língua portuguesa" em meio às frases da "cupópia":"vimbundo está cupopiando no injó do tata" - que quer dizer: "o homem preto está falando na casa do pai". Esse dialeto costuma ser utilizado na segurança do grupo, quando se deseja guardar segredo dos estranhos, como também no cotidiano ou ainda na educação das crianças da comunidade, condição importante no sentido de se preservar essa identidade cultural.

Na explicação de Sérgio LIMOLLI (2008), "Cida”, uma "anguta jocoroto do injó do Cafundó" (uma avó da comunidade do Cafundó), aos 51 anos de idade, faz questão de ensinar aos netos, filhos e ao marido o dialeto "cupóia". No entanto, aos jovens e às crianças da comunidade pouco importa conhecer e perpetuar essa linguagem, e até sentem vergonha de sabê-la, situação que fragiliza a continuidade existencial da "cupópia”.

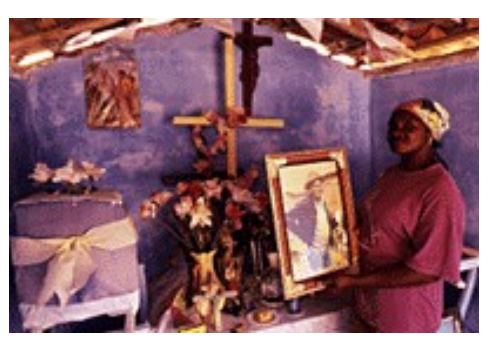




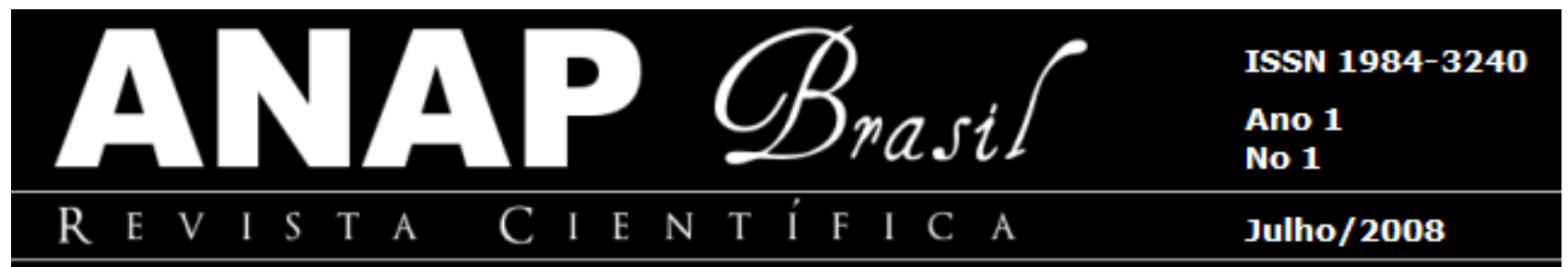

Figura 3 - "Cida" cultuando a imagem do padrinho Otávio

Fonte: LIMOLLI (2008)

Segundo Silvio Vieira de Andrade Filho, conhecido estudioso do Cafundó:

“a preposição 'ca' em boa parte das línguas africanas está associada a algo negativo ou falho. Por isso temos a palavra careca, significando alguém que tem falha nos cabelos; ou caçula, significando o filho menor que é mais desprotegido pela natureza. Com Cafundó não foi diferente. Andrade Filho atribui à própria geografia do lugar, que serviu de proteção e esconderijo àquela comunidade, o motivo para que seus habitantes conseguissem conservar essa língua exótica". LIMOLLI (2008)

Para Rodrigo CUNHA (2008), o Cafundó caracteriza-se como "bairro rural pobre, caboclo, esquecido pelo progresso, exceto por uma peculiaridade", ou seja, a identidade cultural de origem angolana, com o uso de linguagem própria, a "cupópia", que "nem todos falam, mas a maioria entende".

Em entrevista ao Jornal Cruzeiro do Sul (2007), o coordenador da "Associação Remanescente Quimbundo do Cafundó", Marcos Norberto de Almeida (47), bisneto de Efigênia de Almeida Caetano, escrava liberta e uma das herdeiras das terras que deram origem ao Cafundó, explica:

\begin{abstract}
"mesmo depois que a mídia chegou (há 29 anos), não mudou nada aqui" [...] "na prática as dificuldades para garantir a preservação da comunidade continua a mesma. Na aldeia, que hoje tem 22 famílias um total de 105 pessoas, sendo 63 crianças e adolescentes -, há falta de infra-estrutura: as ruas ainda são de terra; existe apenas um telefone público para uso de toda a comunidade, já que nenhuma casa tem o equipamento próprio. A maioria das casas é de alvenaria, há seis anos eram de taipa. Não há escola no bairro, a única unidade fica distante 8 quilômetros. O transporte público atende apenas os estudantes, às $6 h$ e às $12 \mathrm{~h}$. Não há transporte urbano, apesar do centro ficar a 14 quilômetros da aldeia. Também não existe posto de saúde próximo. Mas 'o pior' é a falta de projetos socioculturais por parte de todas as esferas do governo". Continua Marcos, "nunca veio alguém aqui disposto a nos ensinar algo. Vem muita gente aqui, nos estudar, perguntar sobre nossa história, fazer livro, documentário. Mas nos ajudar, ensinar a plantar, construir ou preservar, ninguém veio até hoje" [...] "Ele acredita que além da cultura estar se perdendo, muitas famílias têm deixado o vilarejo atrás de melhores condições"
\end{abstract}

As 'Quilombóias', um grupo de mulheres remanescentes que diariamente se reúnem para confeccionar produtos artesanais tradicionais dos quilombos, tais como 


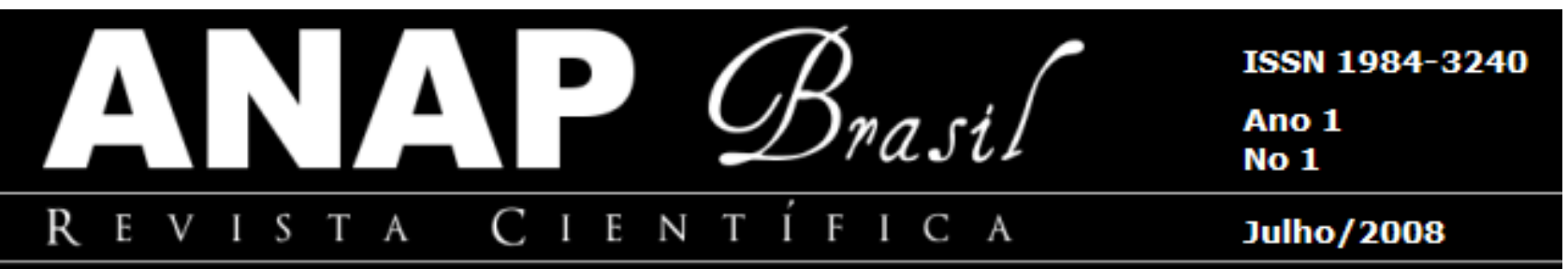

"casinhas" de barro; o 'tambu-um', instrumento musical feito de bambu e couro de cabra, usado em festividades; objetos de ornamentação com sementes e esteiras de palha. $\mathrm{Na}$ tentativa de cultivar e preservar as raízes, esse grupo vende os seus produtos, tanto na comunidade como nas feiras da cidade, e assim, tem preservado e conservado as raízes, além de manter a associação, que lançou uma revista de história do Cafundó, intitulada ‘Dona Ifigênia'. (JORNAL CRUZEIRO DO SUL, 2007)

\section{FUNDAMENTOS TEÓRICOS NA DEFINIÇÃO DO TEMA E DO OBJETO}

\subsection{GEOGRAFIA E TERRITÓRIO: UM ENFOQUE CONCEITUAL NA PAISAGEM PARA O TURISMO}

Entende-se que a relação do Turismo com os fundamentos da Geografia se legitima devido à necessidade constante de avaliação dos impactos no espaço das atividades turísticas e das suas efetivas contribuições para o desenvolvimento local e regional. Além disso, as pesquisas na área da Geografia podem melhorar as políticas públicas e gestão do território devido ao seu objeto, o espaço geográfico que abrange todas as relações homem/meio e homem/homem. A Geografia e o Planejamento interagem e relacionam-se diretamente na definição das diretrizes mais sustentáveis para o uso e ocupação dos solos (ARAÚJO DOS ANJOS, 2008).

Ao considerar os diversos fatores de caráter social, econômico, histórico-cultural e ambiental, entre outros, ancorados na Geografia e territorialidade da comunidade tradicional quilombola, pano de fundo dessa proposta voltada para o Cafundó, significa admitir que esse espaço geográfico, ao se modificar ao longo do tempo, também reproduz as forças das atividades econômicas do sistema capitalista.

No entender de Milton SANTOS (1997: 26-27), o conceito de espaço amplia-se no

"conjunto indissociável de que participam de um lado, certo arranjo de objetos geográficos, objetos naturais e objetos sociais e, de outro, a vida que os preenche 


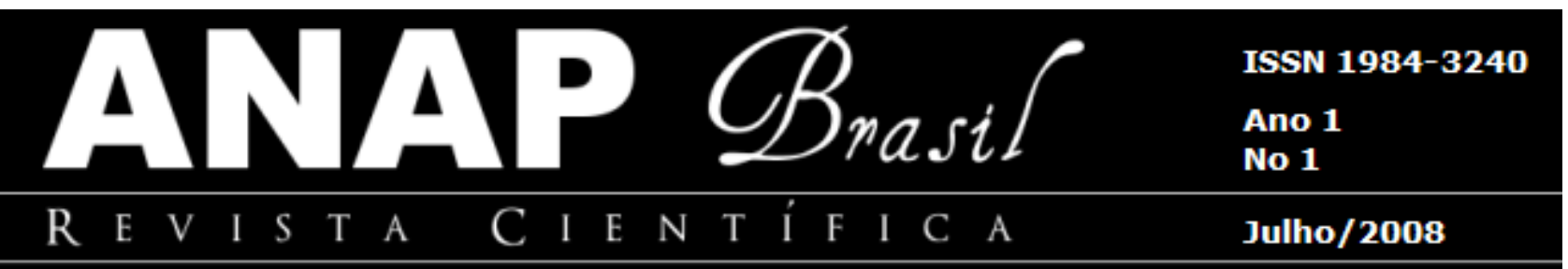

e anima, ou seja, a sociedade em movimento. O espaço, por conseguinte, é isso: um conjunto de formas, contendo cada qual frações da sociedade em movimento"

O "espaço geográfico" deve ser interpretado como o "lugar" das relações humanas em conexão com o meio natural, ou não. Milton SANTOS (1997) ainda esclarece que "o espaço é a união desigual dos tempos", e na Geografia, "mediadas pelo tempo", existem quatro categorias de análise fundamentais tais como "o território, a região, a paisagem e o lugar", que se diferencia através do resultado das relações entre homens e entre estes e a natureza. A organização espacial do "lugar", resultado das ações e decisões dos grupos sociais reflete a cultura humana, ou seja, o patrimônio histórico-cultural como ordenador da paisagem.

Ainda, para esse pesquisador as categorias do método geográfico explicam-se na "estrutura, processo, função e forma", e ajudam na compreensão dessa organização espacial, constituindo uma realidade objetiva, pois o espaço passa a ser considerado enquanto produto social em permanente processo de transformação:

"O espaço impõe sua própria realidade; por isso a sociedade não pode operar fora dele. Consequentemente, para estudar o espaço, cumpre apreender sua relação com a sociedade, pois é esta que dita a compreensão dos efeitos dos processos (tempo e mudança) e especifica as noções de forma, função e estrutura, elementos fundamentais para a nossa compreensão da produção do espaço". (SANTOS, 1997: 49)

A "forma" se constitui no "aspecto visível de uma coisa", como um arranjo ordenado de objetos; a "função" relaciona-se com a tarefa ou atividade esperada de uma forma, pessoa, instituição ou coisa. $\mathrm{Na}$ "estrutura" remete à inter-relação de "todas as partes do todo", seu modo de organização ou construção, e o "processo", como "ação contínua, desenvolvendo-se em direção a um resultado qualquer, implicando conceitos de tempo (continuidade) e mudança" (Santos, 1997: 51).

Ao considerar o binômio, Paisagem e Patrimônio Cultural, também fundamentado na Geografia e no Planejamento, transversal ao conceito de Turismo Étnico na busca de soluções mais sustentáveis para o Cafundó, essa proposta torna-se atrativa, não? 


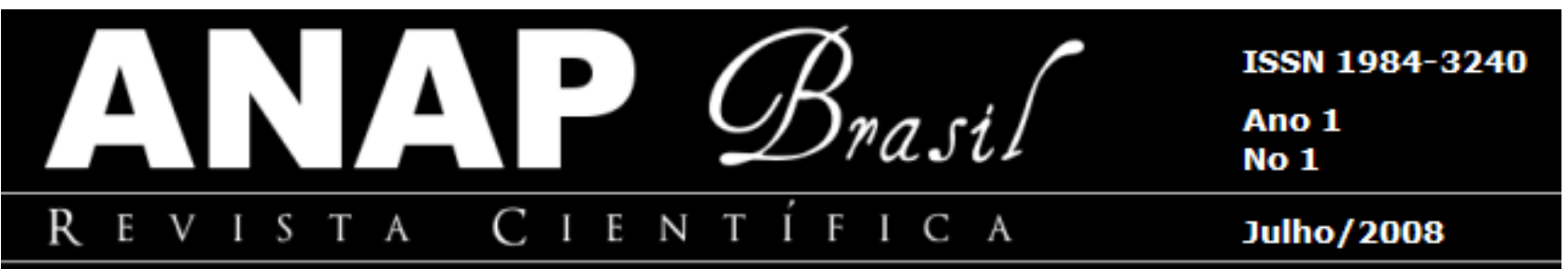

O Turismo apresenta no seu bojo o "princípio estruturador de um processo de desenvolvimento centrado na eficiência econômica, na diversidade cultural, na proteção, conservação do meio ambiente e na eqüidade social". A Declaração dos Direitos Humanos, de 1948, citada no Relatório do Ministério do Turismo, defende uma sociedade mais humanizada, com a possibilidade de melhores condições de cidadania, diretamente relacionada aos direitos de cada um, principalmente no que tange à garantia de trabalho e renda; de educação; liberdade de expressão, e processos participativos de decisão da vida comunitária, na qual se defende a "sustentabilidade sociocultural" como "processo de construção de uma sociedade sustentável e produtiva - uma sociedade que produz e preserva riquezas e não somente acumula lucros" (BRASIL, M.Tur, 2006: 11-12),

A atual transição histórica, pautada na pós-modernidade dos avanços tecnológicos e nas exclusões sociais, influenciadas, tanto pela mídia, como pelos posicionamentos empresariais, inclusive no setor do turismo, urge incorporar ações de sustentabilidade sócio-cultural e responsabilidade sócio-ambiental, entre outras, tanto para garantir o desenvolvimento, como para valorizar o patrimônio cultural, manifestado nos bens materiais, imateriais e ambientais das localidades. Dessa maneira, essa proposta pode colaborar com a redução dos desequilíbrios territoriais e sociais, bem como eliminar as disparidades ambientais de acordo com o princípio da sustentabilidade ambiental, igualdade social e do crescimento da economia, diminuindo os impactos sócioculturais no Cafundó.

Aqui, será adotada a definição de Turismo Étnico impulsionado também pela motivação dos turistas à exploração e conhecimento do território de uma comunidade quilombola, onde a agricultura familiar poderá agregar e promover a valorização econômica das funções em si, bem como das demais atividades complementadas pelas turísticas. A abordagem do estudo do território a partir do binômio Patrimônio e Paisagem visa subsidiar as propostas para o Turismo Étnico sustentável alicerçado nos processos culturais de origem africana, principalmente no patrimônio imaterial, representado nos procedimentos lingüísticos "cupóia" ou "falange", bem como nos costumes dos seus moradores e na tradição do lugar. 


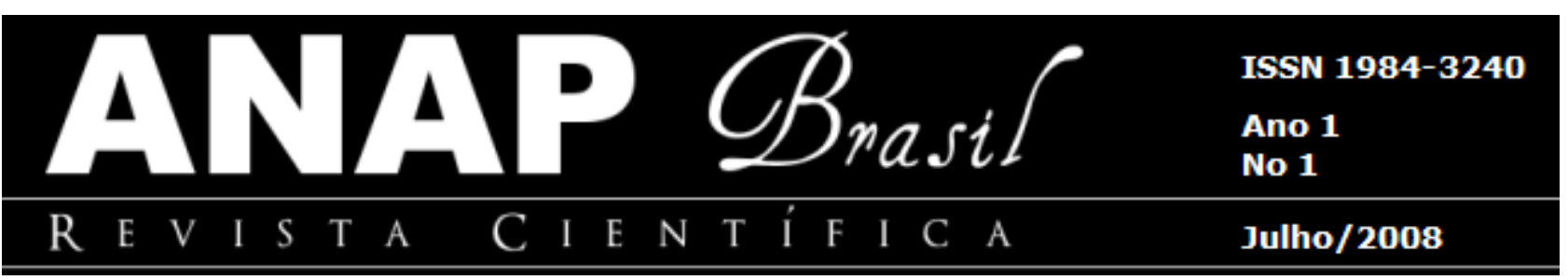

\section{NATUREZA DO PROBLEMA E OBJETIVOS DA PROPOSTA}

Na região do objeto desse estudo, o desenvolvimento econômico caminha "pari passo" aos sérios problemas ambientais gerados pela poluição orgânica e inorgânica dos resíduos sólidos, ou seja, "lixo", na maioria dos municípios ainda a céu aberto, e do esgoto doméstico, principalmente das áreas urbanizadas, despejado in natura nos diversos mananciais de água. Em situação semelhante aos demais municípios da Bacia do Sorocaba/Médio Tietê, somam-se esses, que lançam a maior parte dos seus resíduos diretamente nos mananciais da região, nesse caso, no Pirapora e no Sarapuí, nas proximidades do Cafundó, localizada em Salto de Pirapora - SP (GAIOTTO, 2002)..

Ancorado nos conceitos de geografia e território, principalmente dos territórios tradicionais de comunidades quilombolas, esse trabalho visa desenvolver uma proposta, sistematizada nos pressupostos teóricos e práticos do Turismo Étnico, para a comunidade Cafundó, cujas soluções aos problemas podem garantir o uso sustentável de suas terras; a preservação e conservação da paisagem e do patrimônio cultural, principalmente do dialeto africano "cupópia"; melhores condições de ensino, transporte, emprego e renda aos seus moradores; melhoria da infra-estrutura; segurança alimentar e previdenciária; programas de lazer para os idosos e crianças; garantia de tranqüilidade e qualidade de vida comunitária; valorização e preservação da “arquitetura vernacular", entre outros.

Identificar os atuais elementos ordenadores do perfil ecológico dessa paisagem, que considere a inserção do povoador na natureza, e o relacione ao ambiente físico e cultural, com vistas a compreender a interação do homem/homem e do homem/ambiente, deve contemplar o planejamento participativo nas estratégias de ocupação do território, delimitado pela bacia hidrográfica. O desenvolvimento mais sustentável será entendido como forma de resgatar e valorizar o patrimônio cultural do Cafundó.

Este estudo apresenta ainda finalidades cognitivas e práticas mais amplas, a fim de poder contribuir para a formulação de um modelo de procedimentos de investigação e sustentação do planejamento e gestão do território, dentro das novas perspectivas oferecidas pelo prisma das atividades do Turismo Étnico que possam fomentar pesquisas e medidas mais sustentáveis à preservação do ambiente quilombola. 


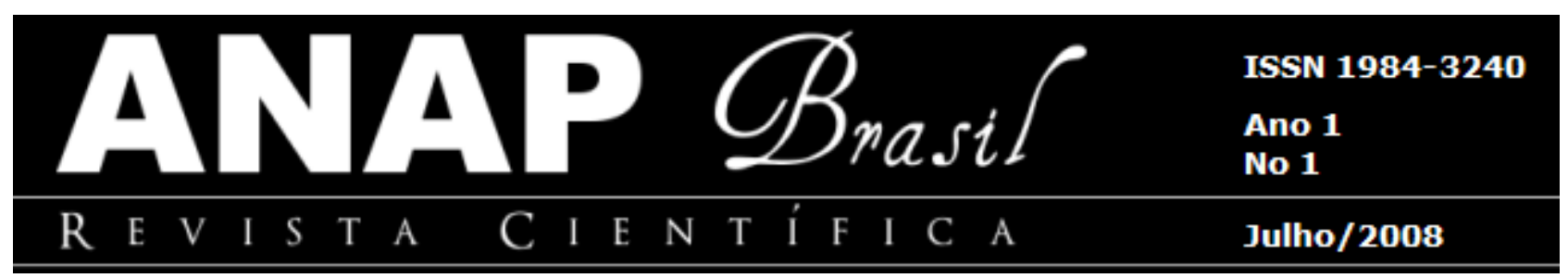

\section{JUSTIFICATIVAS}

O presente trabalho justifica-se na medida em que traz à tona diferentes valores do contexto local relacionados ao regional e às condições naturais do Bioma Mata Atlântica, visando a análise e interpretação da paisagem com a finalidade da ordenação planejada do território, com a participação da comunidade, pressupostos básicos do planejamento participativo, tão preconizado no Estatuto das Cidades para a elaboração dos recentes planos diretores dos municípios envolvidos.

Inicialmente, a escolha dos fatores preponderantes e seus limites, sob o prisma da Geografia e do planejamento, para o recorte deste estudo deram-se a partir da motivação na busca de proposições objetivas para o futuro dessa região, com base nas considerações declinadas por Maria Alice GAIOTTO (2002), em sua tese de doutorado.

Nesse sentido, o estudo do contexto da ocupação do território e dos problemas ambientais decorrentes; da história do assentamento da comunidade quilombola do Cafundó, bem como da sua evolução socioeconômica, cultural e política, oferece subsídios para o delineamento de pesquisas futuras e, também, ao planejamento local, baseado nas atividades turísticas, além de fomentar o cadastramento dos dados históricos. Assim, com vistas à sustentabilidade das atividades turísticas, essa proposta poderá ser incorporada por comunidades similares. O alcance das influências delineadas pelos fatores sócio-culturais e ambientais nem sempre coincide com o perímetro traçado, definidor do espaço geográfico em questão, ou seja, vai além do portal de informações.

\section{ABORDAGEM METODOLÓGICA E PRODEDIMENTOS DA PESQUISA}

Para alcançar os objetivos propostos há que se combinar aos estudos do passado os prováveis levantamentos das condições atuais. A abordagem retrospectiva dos ciclos econômicos, pelos quais passou a comunidade do Cafundó, levará ao entendimento do 


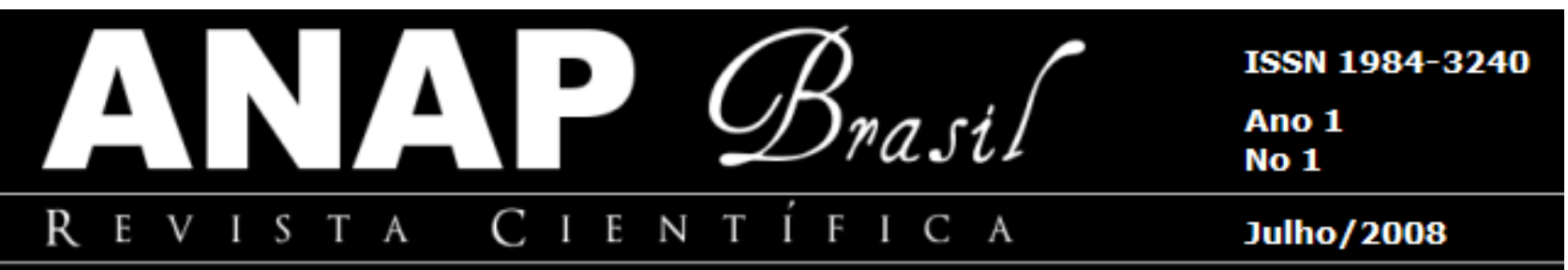

contexto atual. Os levantamentos de dados de campo são essenciais na medida em que permitem distinguir características específicas da lógica do dinamismo dos processos de produção existentes no objeto do estudo.

"O planejamento da produção e a gestão de serviços integrados em unidades regionais definidas por micro-bacias hidrográficas constituem o método de abordagem mais adequado a estudos transdisciplinares que enfoquem o ambiente construído no meio rural, pois abrange todas as possiveis correlações nos diversos âmbitos da arquitetura rural: planos de produção e comercialização agrícola e de serviços não agrícolas; manejo dos recursos naturais, principalmente os recursos hídricos e florestais; ordenação territorial, planejamento ambiental e agro-ecológico; e políticas de desenvolvimento rural sustentável, incorporando modelos de gestão local, educação, assistência técnica, pesquisa e extensão baseadas em conceitos de sustentabilidade e eco-eficiência" ARGOLLO FERRÃO (2006: 4)

Destaca-se a necessidade de constituir a leitura social do território quilombola do Cafundó, suas particularidades e funções estabelecidas a partir de temas do planejamento participativo, tais como distribuição da população no espaço geográfico; processos físico-naturais de constituição da paisagem cultural; desenvolvimento econômico e direito de propriedade das terras; saneamento ambiental e eficiência energética, entre outras.

Amparados em CINTRA (2004), para respaldar as propostas de turismo sustentável, pretende-se realizar estudos que envolvem conhecimentos da "capacidade de carga" na avaliação dos impactos e dos "indicadores de sustentabilidade". A identificação e a valorização do patrimônio histórico-cultural do Cafundó, além de subsidiar propostas de atividades turísticas visa assegurar a volta ao passado.

Importante, ainda, lembrar as possibilidades referentes ao aprimoramento do turismo lastrado na religiosidade, das festas e celebrações dessa comunidade, entre outras programações existentes, num movimento de valorização e fortalecimento de sua cultura, mas também do turismo que valoriza os seus produtos específicos, no sentido de divulgar, preservar e conservar o seu patrimônio cultural. 


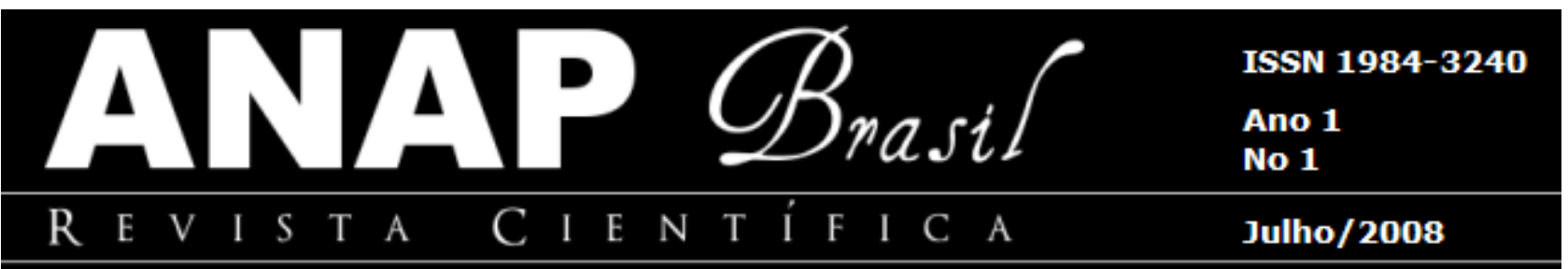

Acompanhados das considerações dos pesquisadores HEUSER e PATRÍCIO (2006), na organização dessa proposta, há que se cuidar dos prováveis efeitos negativos no Cafundó, no sentido de evitar a violência, o aumento da desigualdade social, os problemas de emprego e renda; condições opostas à ideologia do desenvolvimento sustentado, principalmente no que diz respeito à atração do maior lucro econômico gerado versus a qualidade de vida. Aos turistas, muitas vezes, na escolha do lugar dos seus momentos de lazer, pouco importa os residentes, mas a satisfação dos seus desejos, das suas motivações, que acabam por influenciar o signo e o significado da paisagem.

Entende-se que os pressupostos da sustentabilidade devem ser utilizados como fator de abordagem exploratória na questão do planejamento do setor de turismo para colaborar com a redução dos desequilíbrios territoriais e sociais, e das disparidades ambientais de acordo com o princípio de equilíbrio ambiental, de igualdade e de crescimento da economia, minimizando os impactos sócio-culturais. Por exemplo: alteração dos fenômenos migratórios dos mais jovens que incentivem a volta às origens e à comunidade.

Aos desafios em busca de soluções, às crescentes demandas dos serviços ligados ao turismo, no objetivo de reduzir os impactos sobre o ambiente, com a efetiva participação da comunidade cafundoense, deve-se planejar alternativas que sustentem as condições sócio-econômicas e promovam a valorização da paisagem, que priorizem as peculiaridades locais do seu valioso patrimônio cultural, a ser conservado e preservado às gerações futuras, atualmente, ameaçado por fatores endógenos e exógenos.

Desafios à parte, preservar e conservar o patrimônio cultural significa propor diretrizes à solução dos problemas com o objetivo de manter as relações estáveis da comunidade, bem como definir estratégias de ações que valorizem os usos e costumes tradicionais e garantam o freqüente demanda por empregos e renda. Os mais jovens, no afã de se conseguirem melhores condições de vida, migram para as cidades e estabelecem novas formas de representação, que nem sempre correspondem às realidades da origem. 


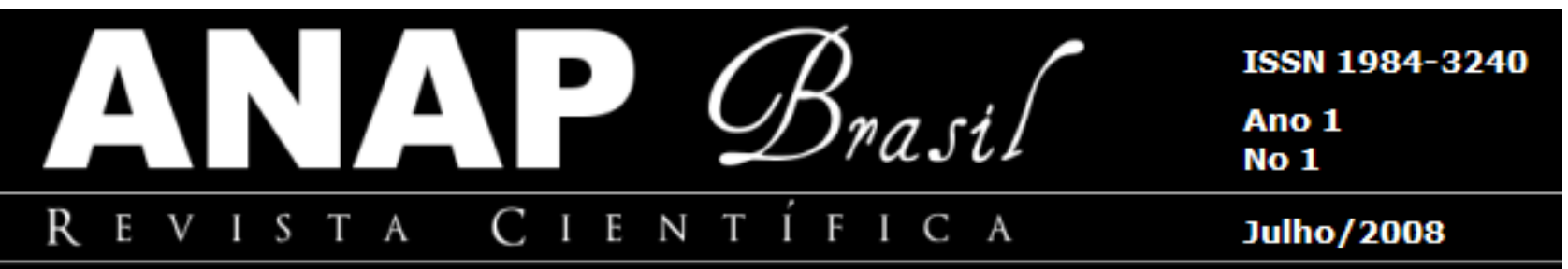

E como planejar as atividades de turismo para garantir a valorização da paisagem cultural das comunidades tradicionais quilombolas, a exemplo do Cafundó?

A missão do planejador e do gestor dessa atividade econômica deve "focar" as peculiaridades locais e jamais transformar os quilombos em hospedagens, situação que reproduziria a forma hegemônica de implantação das condições favoráveis ao turismo. Nesses casos, a diferença faz a diferença, e rompem-se os paradigmas projetuais para dar lugar às novas bases conceituais da educação do visitante para o ambiente, ou seja, há que se condicionar às informações das novas realidades que se propagam do tradicional, interligado às normativas do desenvolvimento e interesses do sistema capitalista, em questão.

\section{CONSIDERAÇÕES FINAIS}

Hoje, a consciência de que não é mais possível continuar como antes é geral, mas as oposições de interesses são cada vez mais sensíveis. Assim, um dos desafios que se impõe aos pesquisadores e planejadores do território seria a busca de soluções para a crescente demanda dos serviços ligados às atividades e empreendimentos sustentáveis, reduzindo os impactos sobre o ambiente, com alternativas que sustentem as suas atividades sócio-econômicas, e promovam a valorização, preservação e conservação da paisagem e do patrimônio cultural às gerações futuras.

No entanto, enquanto imperar a miséria humana em localidades, tal e qual o Cafundó, o conceito de sustentabilidade no Turismo, bem como em todas as frentes econômicas, será simplesmente teórico.

Na pratica, a qualidade do ambiente depende da qualidade de vida, no que diz respeito à saúde, educação, nutrição e habitação, entre outras condicionantes, que, por hora, se ancoram no desenvolvimento econômico. Na alavanca das atividades turísticas, no compromisso com novo humanismo, sob regimes políticos e democracia participativa, há que se garantir a criatividade e a gestão da sociedade, no objetivo de tentar eliminar o distanciamento entre o discurso pragmático, o comportamento individual e as políticas públicas ambientalmente corretas. 


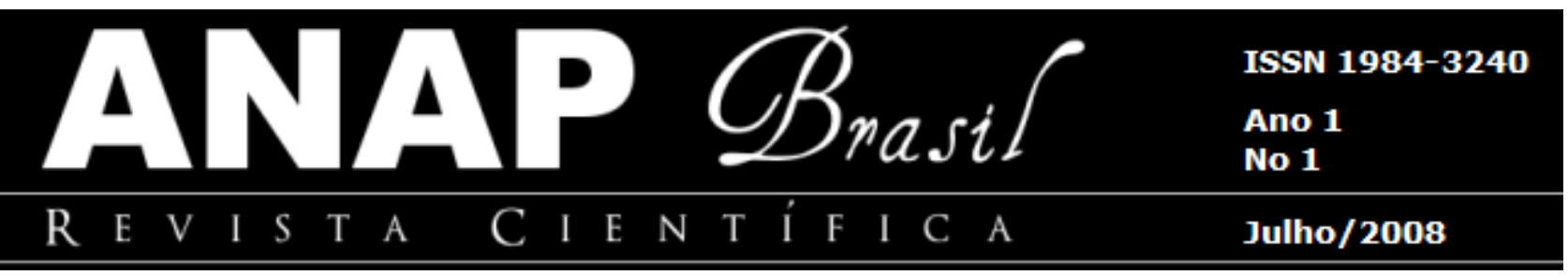

Quiçá o poder público, em parceria com a iniciativa privada e a sociedade civil organizada, realmente, pautem em suas agendas as proposições condicionantes aos ambientes das comunidades tradicionais melhor conservados e preservados, tanto do ponto de vista ambiental, como do patrimônio histórico-cultural, peculiar a cada localidade, sem esquecer as influências de âmbito regional, nacional ou internacional, conforme o caso.

Entende-se que o mais indicado seria a efetivação de tais políticas no sentido de tentar suprir a demanda complementar por empregos e renda, situação que garantiria o desenvolvimento realmente sustentável no contexto sócio-econômico e histórico-cultural da comunidade quilombola do Cafundó, que poderia apresentar como carro chefe o Turismo Étnico.

\section{REFERÊNCIAS}

ANDRADE FILHO, Silvio Vieira de. Espaço do livro: um Estudo Sociolingüístico das Comunidades Negras do Cafundó, do Antigo Caxambu e de seus Arredores. Disponível em: <http://paginas.terra.com.br/educacao/cafundo/cafundo_indice.htm> Acesso em 20 abril 2008.

ARAÚJO DOS ANJOS, Rafael Sanzio. Geografia e Paisagem do Turismo. Apostila da disciplina de mesmo nome, Brasília-DF: UnB, Programa de Especialização em Professor de Turismo, 2008.

ARAÚJO, Rodrigo. Cultura Afro-Brasileira, Quilombos: Cafundó traz a memória na ponta da língua. Disponível em: <http://www.geocities.com/Paris/Jardin/4112/folha \%20brasilis/cafundo.htm> Acesso em: 04 maio 2008.

ARGOLLO FERRÃO, André Munhoz de. Arquitetura Rural e o Agroturismo, in Anais do XXXV Congresso Brasileiro de Engenharia Agrícola, João Pessoa, 31 Jul. a 04 Ago. 2006.

BRASIL, M.Tur. Programa de Regionalização do Turismo, Roteiros do Brasil: Sustentabilidade Sociocultural, Princípio Fundamental. Brasília: Ministério do Turismo, 2006. Disponível em: <http://institucional.turismo.gov.br/regionalizacao/arqreg/doc_download/Sustentabilidade_ Sociocultural_30012007.doc> Acesso em: 30 abril 2008. 


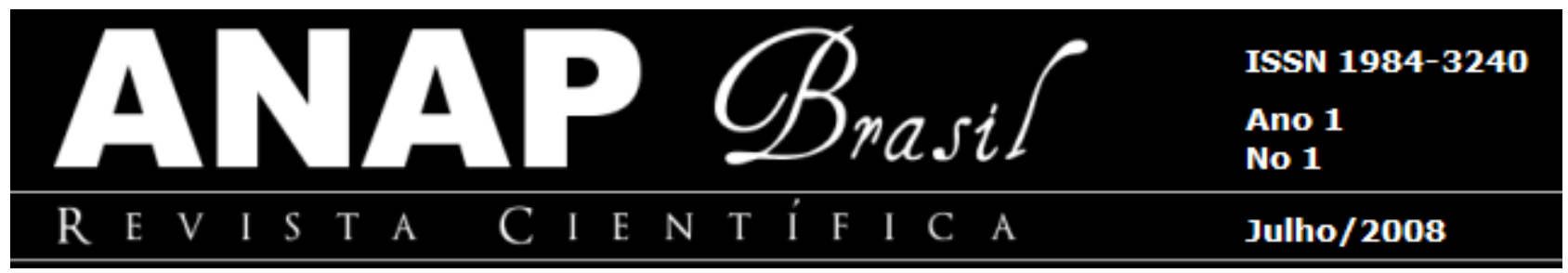

CINTRA, Heitor. Indicadores de Sustentabilidade para o Ecoturismo e o Turismo Rural: uma proposta para Aldeia Velha, Município de Silva Jardim - RJ e Região do Entorno. Dissertação apresentada no programa de Pós Graduação, Niterói/RJ: Universidade Federal Fluminense, 2004.

CUNHA, Rodrigo Resenha: Cafundó: A África no Brasil, VOGT, Carlos \& FRY, Peter (1996). Disponível em: <http://www.comciencia.br/resenhas/negros/cafundo.htm> Acesso em: 28 abril 2008.

GAIOTTO, Maria Alice. Água Viva: Contribuição ao diagnóstico das tendências Ambientais atuais e ao Planejamento da preservação dos Recursos Hídricos da Sub-Bacia do Baixo Rio Sorocaba. Tese de Doutorado, São Paulo: Pós Graduação da Faculdade de Arquitetura e Urbanismo da Universidade de São Paulo, 2002.

HEUSER, Donato Marcelo \& PATRICIO, Zuleica Maria. Agroturismo no Contexto de Núcleos Familiares Receptores de Santa Rosa de Lima (SC): repercussões na qualidade de vida e caminhos para a sustentabilidade. Capitulo 2 - in. Turismo no Espaço Rural: enfoques e Perspectivas / organizadores Anderson Pereira Portuguez ... [et al.]. São Paulo: Roca, 2006. p.17-36.

JORNAL CRUZEIRO DO SUL, Há 141 anos, o Cafundó luta para continuar existindo. Edição de 20 nov. 2007, Sorocaba - SP. Disponível em:

<http://www.cruzeirodosul.inf.br/acervo/2007/11/20/20071120-sorocaba-39593.shtml> Acesso em: 30 abril 2008.

LIMOLLI, Sérgio. "Cupopiá” no Cafundó: língua de origem africana, a "cupópia” sobrevive no interior de São Paulo. Disponível em: <http://www.terra.com.br/istoe/politica/ 140908.htm> Acesso em: 28 abril 2008

$\mathrm{OQ} \mathrm{-} \mathrm{Observatório} \mathrm{Quilombola} \mathrm{Programa} \mathrm{Egbé} \mathrm{Territórios} \mathrm{Negros} \mathrm{de} \mathrm{Koinonia.}$

Disponível em: <http://www.koinonia.org.br/oq/quilombo.asp> Acesso em: 04 maio 2008.

PINHEIRO, Erick. Terras têm importante valor histórico, in Acervo Cruzeiro do Sul. Notícia publicada na edição de 20 nov. 2007. Editora Sorocaba-SP. Disponível em: <http://www.cruzeirodosul.inf.br/acervo/2007/11/20/20071120-sorocaba-40257.shtml> Acesso em: 30 abril 2008.

SANTOS, Milton. Metamorfoses do espaço habitado. Fundamentos teóricos e metodológicos da Geografia. 5 ed. São Paulo: HUCITEC, 1997.

VOGT, Carlos \& FRY, Peter. As formas de expressão na "língua africana do Cafundó", in Revista Ciência e Cultura, vol.57, no.2, São Paulo: Abr.-Jun./2005. Disponível em: $<$ http://cienciaecultura.bvs.br/scielo.php? pid=S0009-67252005000200019\&script=sci_arttext $>$ Acesso em: 01 maio 2008

VOGT, Carlos \& FRY, Peter. Cafundó - A África no Brasil. São Paulo: Companhia das Letras e Editora da UNICAMP, 1996. 376 p. 


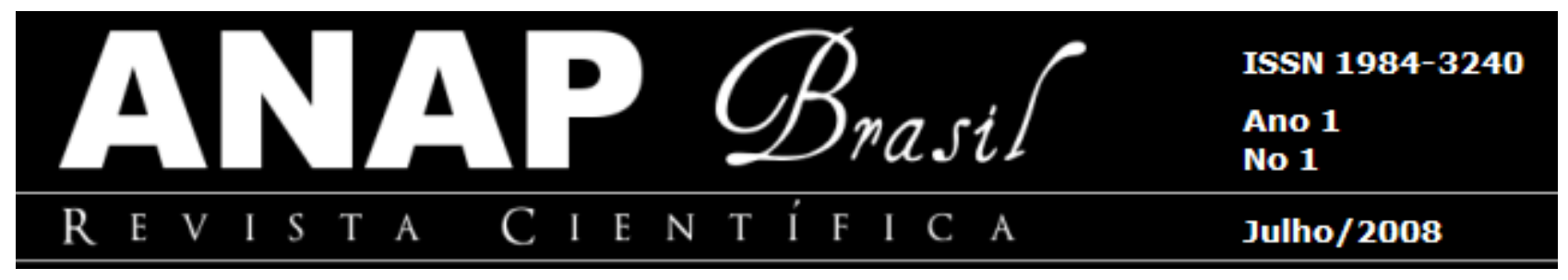

